
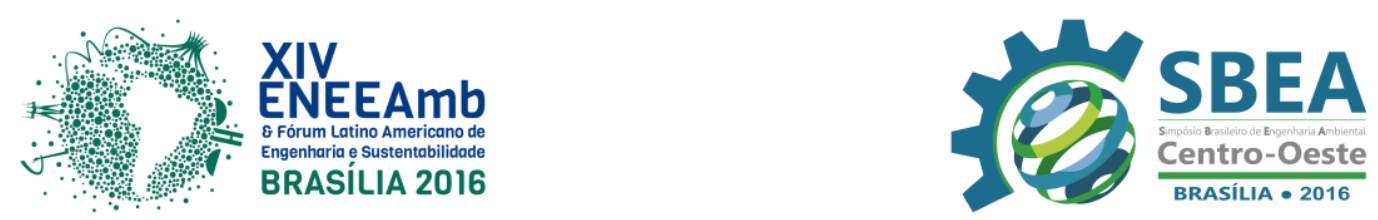

\title{
ÁREAS DEGRADADAS E CONTAMINADAS QUANTIFICAÇÃO DE CONTAMINANTES NAS ÁGUAS SUBTERRÂNEAS DE GOIÂNIA-GO ADVINDOS DE POSTOS DE COMBUSTÍVEIS
}

\begin{abstract}
Ana Taíssa de Resende Falcão - anataissarf@ hotmail.com
Instituto Federal de Educação, Ciência e Tecnologia de Goiás.

Francislainy Teles Almeida - francisteles@ hotmail.com

Instituto Federal de Educação, Ciência e Tecnologia de Goiás.

Roberta Ferreira de Oliveira - robertabioufg@yahoo.com.br Instituto Federal de Educação, Ciência e Tecnologia de Goiás.

Rosana Gonçalves Barros - rosana.ifg@ gmail.com

Instituto Federal de Educação, Ciência e Tecnologia de Goiás.

Rosângela Mendanha da Veiga - rmdaveiga.ifg@gmail.com Instituto Federal de Educação, Ciência e Tecnologia de Goiás.

Viníciu Fagundes Bárbara - viniciu.fagundes@ gmail.com

Instituto Federal de Educação, Ciência e Tecnologia de Goiás.
\end{abstract}

Resumo: Os vazamentos em postos de combustíveis são responsáveis por um grande número de áreas contaminadas no mundo. Os compostos monoaromáticos benzeno, tolueno, etilbenzeno e xilenos são os componentes que mais causam preocupações em áreas contaminadas por hidrocarbonetos, pois apresentam maior mobilidade hídrica e são os mais tóxicos presentes nos combustíveis. Devido a todos os riscos associados às formas de exposição a esses compostos e à grande chance de atingirem o lençol freático, o objetivo do estudo foi quantificar esses elementos químicos nas águas subterrâneas de cinco postos localizados no centro de Goiânia, região onde há muitos estabelecimentos antigos que comercializam combustíveis e cuja concentração de pessoas é elevada. As amostras, coletadas em poços de monitoramento ao final do último período chuvoso, foram analisadas pelo método EPA 8260C. Os resultados obtidos indicaram que as concentrações dos parâmetros químicos avaliados se mostraram abaixo dos limites máximos estabelecidos pela Resolução 42012009 do Conselho Nacional do Meio Ambiente, o que pode ser explicado pela ausência de vazamentos, por processos de remediação bem executados ou pela existência de contaminações em fase inicial que ainda não atingiram as coleções hídricas subsuperficiais. Futuros procedimentos investigatórios envolvendo os solos desses postos deverão ser desenvolvidos para que se verifique a possível existência de contaminação na modalidade sorvida.

Palavras-chave: Combustíveis, passivos ambientais, hidrocarbonetos. 

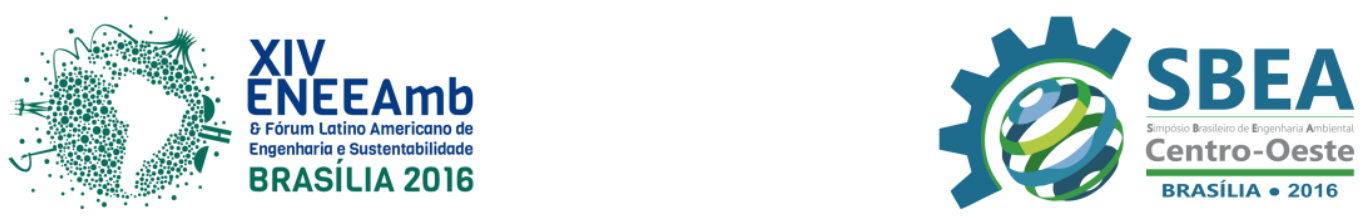

\section{INTRODUÇÃO E OBJETIVOS}

Segundo CETESB (2015), somente em 2015 São Paulo registrou 5.148 áreas contaminadas no estado, sendo que a maior parte delas está associada a postos de combustíveis (74\%). As principais causas para uma porcentagem tão elevada de degradações ambientais associadas a postos são os vazamentos que podem ocorrer em vários processos realizados de forma tecnicamente incorreta nesses locais ou devido a instalações e equipamentos não-estanques.

De acordo com Mindrisz (2006) e Lourenço et al. (2010), a contaminação do solo e das águas subterrâneas em postos pode ocorrer tanto por derrames superficiais nas bombas e bocais de abastecimento dos reservatórios quanto por vazamentos subterrâneos nos tanques e nas tubulações de sucção e retorno de produto. Apenas recentemente, devido a novas exigências estabelecidas pela resolução 273/2000 do Conselho Nacional do Meio Ambiente (CONAMA), os tanques de armazenamento obsoletos/antigos vêm sendo substituídos por outros mais seguros, de parede dupla (JERÔNIMO JÚNIOR \& PASQUALETTO, 2008).

Os maiores problemas de contaminação em postos são atribuídos aos hidrocarbonetos monoaromáticos voláteis benzeno, tolueno, etilbenzeno e xilenos (BTEX), os componentes de maior mobilidade presentes na gasolina. A contaminação das águas subterrâneas por vazamentos é uma das possíveis ameaças à qualidade desse recurso natural devido à alta toxicidade desses quatro tipos de hidrocarbonetos - especialmente do benzeno -, poderosos depressores do sistema nervoso central (SILVA et al., 2002). Nesse sentido, a exposição aos BTEX em baixas concentrações por um longo período pode causar uma série de efeitos crônicos. O benzeno, o mais tóxico, pode causar depressão das células sanguíneas, danos à medula óssea, leucemia e câncer de fígado. $\mathrm{O}$ tolueno apresenta toxicidade sistêmica moderada, e, quando inalado, compromete o sistema nervoso central, além de apresentar efeitos embriotóxico e fetotóxico. O etilbenzeno e o xileno desencadeiam baixa toxicidade sistêmica, entretanto, também são depressores do sistema nervoso central (SOUZA et al., 2014).

Os centros urbanos, devido à elevada quantidade de postos de combustíveis, são áreas muito sujeitas a contaminações ambientais por hidrocarbonetos. Uma vez introduzidos na subsuperfície, os combustíveis advindos dos Sistemas de Armazenamento Subterrâneos de Combustíveis (SASCs) de postos costumam alcançar o lençol freático e, carreados pelo fluxo das águas subterrâneas, podem se acumular sob fundações, redes de telefonia ou elétrica e galerias pluviais, dentre outros (MINDRISZ, 2006), favorecendo inclusive riscos de explosões. Além disso, a área impermeável dos centros urbanos normalmente é maior e favorece o acúmulo de contaminantes submetidos a maiores pressões.

Devido aos riscos associados e à escassez de informações científicas sobre o possível comprometimento das coleções hídricas subterrâneas de Goiânia por hidrocarbonetos, principalmente de sua região central - onde se localizam alguns dos postos de combustíveis mais antigos da cidade, com SASCs de idades avançadas -, é necessário o desenvolvimento de pesquisas nessa área.

Portanto, o objetivo deste trabalho foi identificar possíveis áreas da região central de Goiânia cujas águas subterrâneas foram contaminadas por BTEX advindos de postos, comparando as concentrações encontradas com os valores máximos estabelecidos pela legislação ambiental vigente. 


\section{METODOLOGIA}

Primeiramente, foi feita a seleção de cinco postos de abastecimento localizados na região central de Goiânia, aqui denominados de Posto 1, 2, 3, 4 e 5. Uma vez em suas dependências, realizou-se uma avaliação preliminar para identificação de possíveis irregularidades que pudessem indicar eventuais sinais de situações de contaminação.

Para a determinação dos compostos de BTEX foram obtidas amostras de águas provenientes de poços de monitoramento existentes nos estabelecimentos, perfazendo o total de cinco alíquotas. Uma vez coletadas com o auxílio de bailers (Figura 1), as amostras foram acondicionadas em frascos de polietileno devidamente armazenados em caixa de isopor até a chegada ao laboratório. Quando o poço de monitoramento não apresentou o volume hídrico amostral mínimo suficiente, foram obtidas alíquotas compostas advindas de outros poços de mesmo estabelecimento. As coletas foram realizadas em março/2016, ao final do período chuvoso, quando o nível freático se apresenta mais elevado.

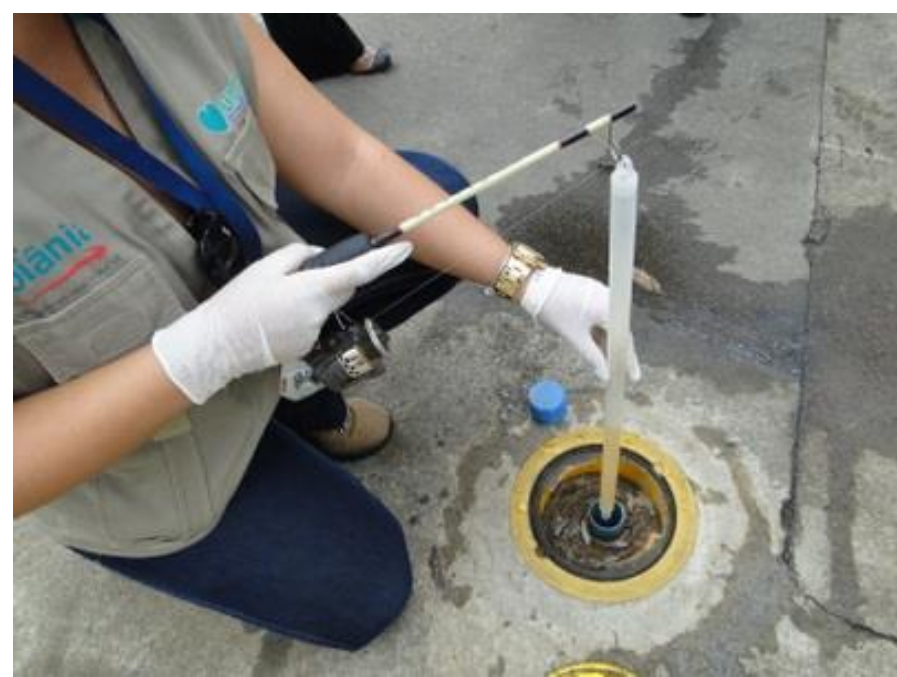

Figura 1 - Um dos bailers utilizados na obtenção das amostras.

Tabela 1 - Dados das amostras de água subterrânea coletadas nos poços de monitoramento.

\begin{tabular}{|c|c|c|c|c|}
\hline Identificação & $\begin{array}{c}\text { Data da } \\
\text { coleta }\end{array}$ & $\begin{array}{l}\text { Horário da } \\
\text { coleta }(\mathrm{h})\end{array}$ & $\begin{array}{c}\text { Coordenadas geodésicas } \\
\text { dos pontos de coleta }\end{array}$ & Observações \\
\hline Posto 1 & \multirow{5}{*}{$23 / 03 / 2016$} & $8: 48$ & $\begin{array}{l}16^{\circ} 40 ’ 01.66^{\prime \prime} \mathrm{S} \\
49^{\circ} 15^{\prime} 29.86^{\prime \prime} \mathrm{W}\end{array}$ & $\begin{array}{l}\text { Amostra } \\
\text { simples }\end{array}$ \\
\hline Posto 2 & & $9: 25$ & $\begin{array}{l}16^{\circ} 39^{\prime} 54.84^{\prime \prime} \mathrm{S} \\
49^{\circ} 15^{\prime} 37.72^{\prime \prime} \mathrm{W}\end{array}$ & $\begin{array}{l}\text { Amostra } \\
\text { composta }\end{array}$ \\
\hline Posto 3 & & $10: 00$ & $\begin{array}{c}16^{\circ} 39^{\prime} 49.08^{\prime \prime} \mathrm{S} \\
49^{\circ} 15^{\prime} 30.66^{\prime \prime} \mathrm{W}\end{array}$ & $\begin{array}{l}\text { Amostra } \\
\text { composta }\end{array}$ \\
\hline Posto 4 & & $10: 18$ & $\begin{array}{l}16^{\circ} 39^{\prime} 54.20^{\prime \prime} \mathrm{S} \\
49^{\circ} 15^{\prime} 49.11^{\prime \prime} \mathrm{W}\end{array}$ & $\begin{array}{l}\text { Amostra } \\
\text { composta }\end{array}$ \\
\hline Posto 5 & & $10: 40$ & $\begin{array}{c}16^{\circ} 40^{\prime} 7.86^{\prime \prime} \mathrm{S} \\
49^{\circ} 15^{\prime} 37.31 ” \mathrm{~W}\end{array}$ & $\begin{array}{l}\text { Amostra } \\
\text { composta }\end{array}$ \\
\hline
\end{tabular}



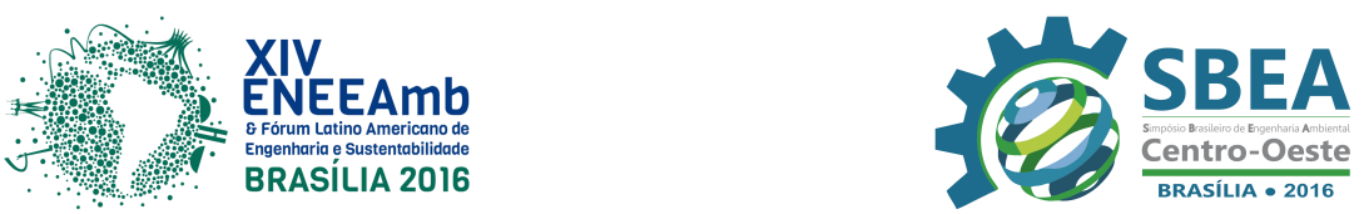

As análises foram realizadas em obediência ao método EPA 8260C. As concentrações de BTEX obtidas com as análises foram comparadas com os Valores de Investigação para águas subterrâneas estabelecidos pela Resolução $n^{\circ}$ 420/2009 do CONAMA.

Os trabalhos de campo foram desenvolvidos com o acompanhamento de profissionais da Agência Municipal do Meio Ambiente de Goiânia (AMMA).

\section{RESULTADOS E DISCUSSÕES}

\subsection{Avaliação preliminar}

Embora todos os estabelecimentos inspecionados fossem dotados dos dispositivos mínimos de engenharia ambiental para evitar a contaminação do meio natural, inconformidades foram observadas, como existência de tanques muito antigos, pisos com rachaduras, canaletas coletoras de efluentes danificadas, caixas separadoras de água e óleo sujas e demonstrando não terem sido submetidas às devidas manutenções periódicas e bombas e filtros com ausência de sumps, dentre outras (Figura 2).
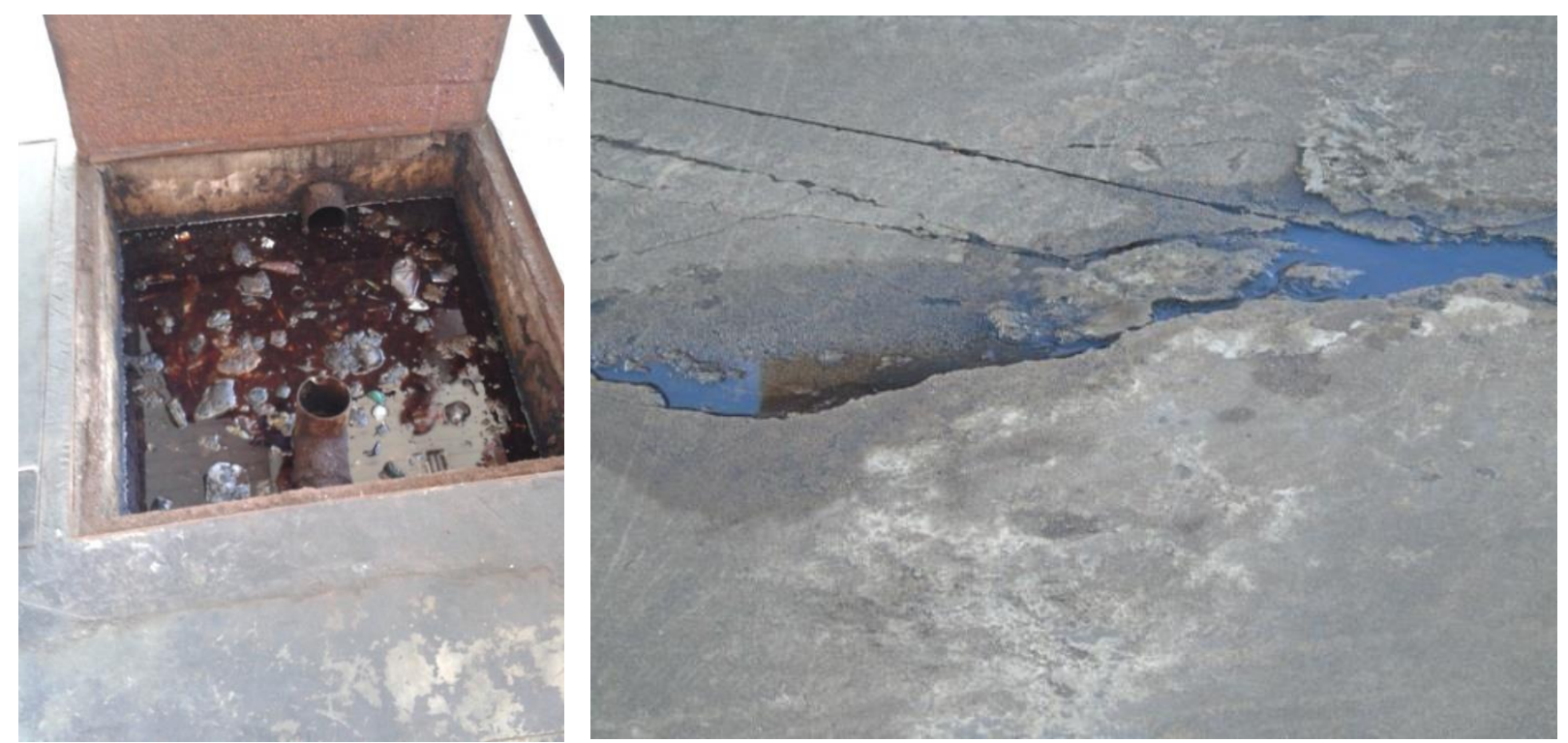

Figura 2 - Duas imagens referentes respectivamente ao Posto 1 e 4 nas quais se observa uma caixa separadora de água e óleo suja, o que reduz sua eficiência, e rachaduras no piso da pista de abastecimento favorecendo situações de contaminação ambiental.

\subsection{Análises Laboratoriais}

Os resultados das concentrações de BTEX são apresentados na Tabela 2, a seguir, assim como a comparação com os Valores de Investigação estabelecidos pela Resolução ${ }^{\circ}$ 420/2009 do CONAMA. 
Tabela 2 - Resultados das análises de BTEX para as amostras de águas dos poços de monitoramento dos postos avaliados.

\begin{tabular}{|c|c|c|c|c|c|c|}
\hline \multirow{2}{*}{ Parâmetros } & \multicolumn{5}{|c|}{ Concentrações $(\mu \mathrm{g} / \mathrm{L})$} & \multirow{2}{*}{$\begin{array}{c}\text { CONAMA } \\
420(\mu \mathrm{g} / \mathrm{L})\end{array}$} \\
\cline { 2 - 7 } & Posto 1 & Posto 2 & Posto 3 & Posto 4 & Posto 5 & 5 \\
\hline Benzeno & $<0,02$ & $<0,02$ & $<0,02$ & $<0,02$ & $<0,02$ & 500 \\
\hline Tolueno & $<0,02$ & $<0,02$ & $<0,02$ & $<0,02$ & $<0,02$ & 300 \\
\hline Etilbenzeno & $<0,01$ & $<0,01$ & $<0,01$ & $<0,01$ & $<0,01$ & 700 \\
\hline Xilenos & $<0,01$ & $<0,01$ & $<0,01$ & $<0,01$ & $<0,01$ & 500 \\
\hline
\end{tabular}

Embora durante os trabalhos de campo tenham sido obtidas informações e observados indícios de que três dos cinco postos apresentavam histórico de contaminação ambiental, as concentrações de BTEX nas amostras coletadas neste estudo se apresentaram abaixo dos limites máximos estabelecidos pela Resolução no 420 do CONAMA. Esses resultados ambientalmente satisfatórios para as águas subterrâneas podem ter pelo menos três explicações distintas: (i) ausência propriamente dita de contaminações; (ii) eficiência dos processos de remediação empregados no passado para remoção dos hidrocarbonetos detectados nos postos contaminados ou (iii) existência de contaminações iniciais ou apenas em fase sorvida (restrita ao solo), ou seja, que ainda não atingiram as coleções hídricas subterrâneas.

Resultados semelhantes foram obtidos em estudo desenvolvido por Bezerra et al. (2012) e Brito et al. (2004), vez que a maior parte das amostras de água subterrânea analisadas por esses pesquisadores apresentou concentrações de BTEX abaixo dos limites legais. Por outro lado, Silva et al. (2002) constataram que, dois anos após a ocorrência de um grande vazamento em um posto de combustível, em $20 \%$ das residências localizadas em suas proximidades os moradores estavam consumindo água com concentração de benzeno cem vezes maior que a máxima permitida pela Portaria de Potabilidade nº 1469, do Ministério da Saúde.

Nesse sentido, Corseuil et al. (2004) demonstraram que um dos principais fatores para a dispersão acelerada de plumas de contaminação é a presença de etanol. Segundo esses autores, a presença de $10 \%$ de álcool já é capaz de alterar significativamente a solubilidade de hidrocarbonetos na água, favorecendo a contaminação do lençol freático. A gasolina brasileira contém cerca de $25 \%$ de etanol (BRASIL, 2006).

Apesar de os resultados do presente estudo terem demonstrado ausência de contaminação ambiental nas águas subterrâneas, essa hipótese ainda não está descartada para os estabelecimentos avaliados. É necessária a realização de estudo complementar da qualidade do solo já que, como discutido por Day et al. (2001), o destino e transporte de 

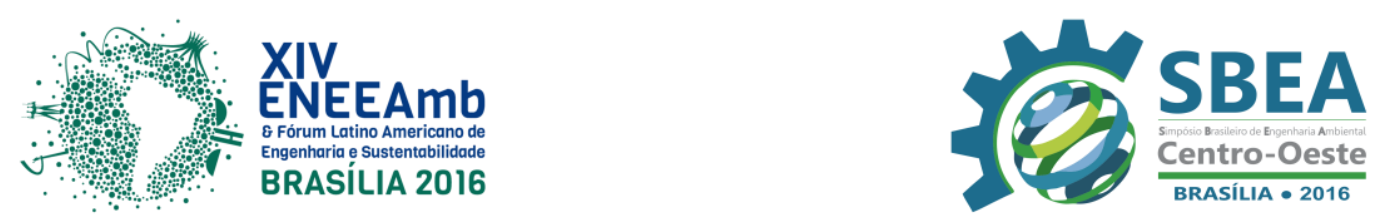

componentes de combustível no subsolo são determinados não somente pelas características hidrodinâmicas, mas também geológicas. Portanto, é possível que contaminantes estejam presentes no solo dos empreendimentos estudados na forma sorvida. Pequenos vazamentos, muitas vezes não identificados e restritos à zona insaturada do solo, podem causar grandes impactos devido ao fato de geralmente só serem percebidos depois de muito tempo.

\section{CONSIDERAÇÕES FINAIS}

O estudo demonstrou resultados satisfatórios sobre a qualidade da água subterrânea dos postos de combustíveis estudados, não tendo sido comprovada contaminação do tipo fase livre ou dissolvida. Entretanto, os riscos de contaminação ainda não estão descartados, pois é necessária a realização de estudo da qualidade do solo desses estabelecimentos para avaliar se há indícios de contaminação do tipo fase sorvida.

\section{REFERÊNCIAS}

BEZERRA, P.G; CELINO, J.J.; GARCIA, K.S.; OLIVEIRA, M.R. Indicadores geoquímicos de contaminação por compostos orgânicos voláteis em águas subterrâneas da Bacia do Rio Lucaia, Salvador, Bahia. Revista Brasileira de Geociências, São Paulo, v. 42, 2012.

BRASIL. Ministério da Agricultura, Pecuária e Abastecimento. Portaria ministerial $\mathrm{n}^{\circ}$ 51, de 22 de fevereiro de 2006.

BRITO, F.V.; OLIVEIRA, A.S.; NEVES, H.C.; AZEVEDO, J.A.T.; BHERING, D.L.; REIS, S.M.; MACHADO, M.C.S.; AZEVEDO, G.C.; CARVALHAES, G.K. Estudo de contaminação de águas subterrâneas por BTEX oriundos de postos de distribuição no Brasil. In: $3^{\circ}$ Congresso Brasileiro de P\&P em Petróleo e Gás. Salvador, 2 a 5 de outubro. 2004.

CETESB - Companhia Ambiental do Estado de São Paulo. Relação de áreas contaminadas e reabilitadas. São Paulo, 2015. Disponível em: $<$ http://areascontaminadas.cetesb.sp.gov.br/wpcontent/uploads/sites/45/2013/11/Totaliza\%C3\%A7\%C3\%A3o-departamento.pdf $>$. Acessado em 22/3/2016.

CORSEUIL, H.X.; KAIPPER, B.I.A.; FERNANDES, M. Cosolvency effect in subsurface systems contaminated with petroleum hydrocarbons and ethanol. Water research, [S.I.]. 2004.

DAY, M. J.; REINKE, R. F.; THOMSON, J. A. M. Fate and transport of fuel components below slightly leaking underdroung storage tanks. Applied Hydrology Associates, Denver, p. 21-28, 2001. 
LOURENÇO, E.S.O.; CARDOSO, D.L.; MATHEUS, F.H. Ação dos meios reativos peróxido de hidrogênio e carvão ativado na remediação de solos contaminados por BTEX. Rev. Eng. Agríc., Jaboticabal, SP, v. 30, n. 1, p. 130-137, 2010.

JERÔNIMO JUNIOR, J.; PASQUALETTO, A. Contaminação ambiental movida por postos retalhistas de combustíveis. 2008. Disponível em: < http://www.pucgoias.edu.br/ucg/prope/cpgss/ArquivosUpload/36/file/CONTAMINA\%C3\%8 7\%C3\%830\%20AMBIENTAL\%20POR .pdf >. Acessado em 21/3/2016.

MINDRISZ, A.C. Avaliação da contaminação da água subterrânea de poços tubulares, por combustíveis fósseis, no município de Santo André, São Paulo: uma contribuição à gestão ambiental. 2006. Tese de Doutorado. Disponível em: <http://www.teses.usp.br/teses/disponiveis/85/85134/tde-28092006-091158/pt-br.php>.

SILVA, R. L. B.; BARRA, C. M.; MONTEIRO, T. C. N.; BRILHANTE, O. M. Estudo da contaminação de poços rasos por combustíveis orgânicos e possíveis consequências para a saúde pública no Município de Itaguaí, Rio de Janeiro, Brasil. Cad. Saúde Pública, Rio de Janeiro, v. 18, n. 6, p. 1599-1607, 2002.

SOUZA, E.C.; VESSONI-PENNA, T.C.; OLIVEIRA, R.P.S. Biosurfactant-enhanced hydrocarbon bioremediation: An overview. International Biodeterioration \& Biodegradation, v. 89, p. 88-94, 2014. 